\title{
GDP growth and convergence determinants in the European Union: a crisp-set analysis
}

\author{
Paulo Ferreira, ${ }^{1}$ Andreia Dionísio ${ }^{2}$
}

\begin{abstract}
Economic growth and convergence remains a topical issue. This study uses a crisp-set qualitative comparative analysis of data from European Union countries in order to establish which conditions could be considered necessary and sufficient to make these countries converge. Based on six different conditions (GDP, secondary education, life expectancy, fertility rate, government consumption and inflation rate), this study finds that the main conditions affecting convergence are government consumption ratio (lower levels will increase convergence), education levels and life expectancy (both with a positive influence on convergence). The first two conditions show quite interesting results: in fact, reduction of government expenditure and budget constraints are an open debate; and the European Union's aim to become a more competitive economy can only be attained with higher levels of education.
\end{abstract}

Key words: Convergence, crisp-set qualitative comparative analysis, European Union, necessary conditions, sufficient conditions

JEL Classification: C82, O400

Received: 6 May 2016/Accepted: 23 September 2016/Sent for Publication: 9 December 2016

\section{Introduction}

Since the seminal studies by Solow (1956), Barro et al. (1991) and Barro and Sala-iMartin (1992), several other studies have also dealt with economic growth and economic convergence. Many of these studies use regional data (see, for example, Carlino and Mills, 1993, 1996 for the USA and Bartkowska and Riedl, 2012 for Europe) or data for several countries (see for example Bernard and Durlauf, 1995, Barro, 2016, or Walheer, 2016, among others). Different methodologies have been used to analyze evidence on this topic: ordinary least squares (e.g.Barro, 1996), time series analysis (Bernard and Durlauf, 1995), Bayesian methods (Sala-i-Martin et al., 2004, Cuaresma et al., 2014), and several other approaches (see, for example, Walheer, 2016).

\footnotetext{
${ }^{1}$ CEFAGE-UE, IIFA, Universidade de Évora, Largo dos Colegiais 2, 7000 Évora, Portugal. Escola Superior Agrária de Elvas, Instituto Politécnico de Portalegre, Portugal. Universidade Europeia, Portugal. Corresponding author: pjsf@uevora.pt

${ }^{2}$ CEFAGE-UE, IIFA, Universidade de Évora, Largo dos Colegiais 2, 7000 Évora, Portugal.

() 2016 by the authors; licensee Review of Economic Perspectives / Národohospodářský obzor, Masaryk University, Faculty of Economics and Administration, Brno, Czech Republic. This article is an open access article distributed under the terms and conditions of the Creative Commons Attribution 3.0 license, Attribution - Non Commercial - No Derivatives.
} 
This study is different from the above-mentioned works, because although our objective is to study the determinants of GDP growth and convergence, we center our analysis on the European Union (EU) countries, and use a different methodology: a crisp-set qualitative comparative analysis (csQCA). Applying this methodology to the economic growth problem is the paper's main innovation.

Using information for all EU countries, with data from the period between 2000 and 2013 (according to availability), this study sets out to analyze what conditions are necessary and sufficient in order to achieve higher growth rates and convergence. The conditions used in this analysis are in line with the study by Barro (1996). GDP growth and convergence remains a topical issue, because it is expected that poorer countries will catch up with richer ones in the future (see for example Aghion et al., 2005). Furthermore, economic integration will, in theory, also promote real convergence, which makes the EU an interesting area to analyze.

To our knowledge, few studies have applied qualitative comparative analysis to convergence or economic growth. Vis et al. (2007) use fsQCA to compare economic performance between countries and Bilman and Turkeli (2013) use the same methodology to analyze the interaction between international trade and economic growth. However none of these studies analyze the convergence process. Haynes $(2014,2015)$ uses csQCA, combining it with cluster analysis, with the objective of studying economic policy convergence in the Eurozone.

The next section contains a literature review on economic growth and convergence, and presents the various features of this interesting research topic. In Section 3 we present the methodology used in this study, including the studies referred to in the previous paragraph. Our results are presented and explained in Section 4 and we conclude in Section 5 .

\section{Literature review on economic growth and convergence}

As previously mentioned, the literature contains a vast number of studies related to growth theories. Those studies do not agree as to which variables should be used to analyze economic growth and to explain cross-country differences, which could be explained by many growth theories (Durlauf et al., 2008). These different theories offer more than 140 possible variables for the study of economic growth (Durlauf et al., 2005).

In their study devoted to reviewing this issue, Durlauf et al. (2008) consider seven broad growth theories and their authors of reference: the neoclassical growth theory, demography/health, macroeconomic policy, religion, geography, ethnic fractionalization and institutions. These authors also argue that regional heterogeneity could explain some differences in growth (in this case, the continent where the countries belong). Including information on all these theories, the authors fail to find strong evidence for those growth theories. Nevertheless, differences in macroeconomic policies and unknown heterogeneity associated with regional groupings are the main determinants of growth differences between countries. These findings do not call previous studies into question, but draw attention to the importance of continued study in this field. 
Besides the large number of variables referred to by the previous study, a wide variety of methods have also been applied in this research area. Regarding convergence between countries, some studies, for example, use cross-section regressions: Baumol (1986), Barro, (1991), Paap et al. (2005), Alfo et al. (2008), and Owen et al. (2009) are just some examples of this type of study. The results of these and other studies do not coincide. Some authors, such as Quah (1993, 1996, 1997), Kumar and Russell (2002) and Johnson (2005) argue that the differences in results could be due to disparities in the distribution of labour productivity in the world. The incorporation of human capital into theoretical endogenous growth models (Lucas, 1988, and Romer, 1990) led to an increase in studies on this topic (e.g. Henderson and Russell, 2005 and Badunenko et al., 2013).

The evolution of econometrics and advances in time series, namely unit root and cointegration tests, enabled another type of study. Using data for different countries, studies like those by Bernard and Durlauf (1995), Evands and Karras (1996), Nahar and Inder (2002), Strazicich et al. (2004) and Brada et al. (2005) are examples of these types of methodologies: these authors use different tests and analyze the stochastic properties of macroeconomic data. Naturally, their conclusions differ as to whether the respective economies are converging, and if so at what speed.

The majority of studies analyzing convergence between nations are based on GDP aggregates (in particular, per capita GDP) ${ }^{3}$. However, it is also possible to study other kinds of variables, particularly income. This type of convergence is more commonly used in studies analyzing regional data. Examples of convergence studies applied to regional data are those by Carlino and Mills (1993, 1996), Loewy and Papell (1996), Carrion-i-Silvestre and German-Soto (2007), Battisti and Di Vaio (2008) and Montañés and Olmos (2014). These studies also use a variety of methodologies.

Independently of the above-mentioned studies, and despite the fact that growth and convergence can be explained by a large number of variables, this study focuses its analysis on the variables presented by Barro (1996), who studied differences in growth rates across countries using the following variables (all the impacts referred to are considered while keeping all other variables constant):

- $\quad \log (\mathrm{GDP})$. The initial level of GDP has a negative impact on growth rates;

- male secondary and higher schooling, which will increase countries' growth potential;

- $\quad \log$ (life expectancy), also increasing growth;

- $\quad \log (\mathrm{GDP})^{*}$ male schooling, a combination of variables, which is expected to have a positive impact on growth;

- $\quad \log$ (fertility rate), with a negative impact on growth;

- government consumption ratio, which will break economic growth;

- $\quad$ rule-of-law index, measuring country risk and its importance in growth;

- terms-of-trade change, which will benefit growth;

- democracy index (and its square) measuring the importance of democracy in growth;

\footnotetext{
${ }^{3}$ Involving economic analysis, it is possible to use any variable and verify if it has some kind of convergence. For example, Brada et al. (2005) also analyze convergence for monetary aggregates.
} 
- inflation rate, which will have a negative impact on growth;

- dummies to detect regional heterogeneity, comparing regions' growth patterns (dummies for countries belonging to Sub-Saharan Africa, Latin America and East Asia).

We do not use all of these variables in our study, and explain the exclusions we have made in the following section.

\section{Crisp-set qualitative comparative analysis and data}

The main objective of this study is to determine the necessary and sufficient conditions for convergence in the EU, using crisp-set qualitative comparative analysis (csQCA). Part of a group of methodologies of qualitative comparative analysis, csQCA aims to identify the necessary and sufficient conditions for a given binary outcome ${ }^{4}$. Generally, qualitative comparative analysis (QCA) is a technique aiming to determine logical conclusions from a given dataset. After considering all the possible combinations of conditions, qualitative comparative analysis applies logical inference to determine how conditions explain a given outcome, distinguishing between necessary and sufficient conditions.

In particular, csQCA is a methodology that aims to "simplify complex data structures in a logical and holistic manner" (Ragin, 1987), and which has the advantages of both qualitative and quantitative analysis (Ragin, 2008). Introduced in the Sociology literature by Ragin (1987), csQCA is now used in several other research areas, including economics. This method is well suited to small or medium-sized samples, which is a further advantage when compared to regression analysis (see for example Vis, 2012). Considering that our sample contains the twenty-eight EU countries, this methodology is good in this case.

As stated previously, qualitative comparative analysis is able to capture the necessary and sufficient conditions for a given outcome. Necessary conditions are those where "an outcome can be attained only if the attribute in question is present", while sufficient conditions denote those where the outcome "will always be obtained if the attribute in question is present" (Fiss, 2007).

In this methodology, necessary conditions are measured by their consistency, which is a measure of the degree to which each case corresponds to the given outcome. This study uses a measure of consistency by Ragin (2006), which attributes penalties for severe inconsistencies. When it comes to sufficient conditions, this study uses the truth table algorithm (see Ragin, 2008). For a more complete analysis of the csQCA formulation, see Rihoux and De Meur (2008).

As previously stated, we have two objectives. Firstly, we want to analyse whatthe main conditions are for countries to have higher GDP growth rates than the EU, using csQCA. This methodology uses conditions (independent variables, in regression nomenclature) to explain a given outcome (dependent variable). We have chosen five variables from

\footnotetext{
${ }^{4}$ Other methodologies include fuzzy-set comparative qualitative analysis (fsQCA), which is able to work with continuous sets, and multi-value data qualitative analysis (mvQCA), which uses categorical variables with more than two values. For more information see Ragin (2008).
} 
those listed by Barro: GDP, life expectancy, fertility rate, government consumption ratio and inflation rate. We have also adapted the secondary education level variable, so as not to distinguish between male and female (considering there is no gender discrimination in the EU). We will use these six conditions to evaluate convergence in EU countries.

From the original study (Barro, 1996), the following conditions were excluded:

- $\quad$ the interaction between GDP and male schooling. This is excluded because it might make the csQCA analysis more complex (in the original work, this variable is irrelevant);

- the rule-of-law index. This condition makes no sense in EU countries, where country risks are negligible;

- terms-of-trade change. This is a condition used mainly to distinguish between developed and less developed countries;

- the democracy index. Neither variable (original or square) makes sense in the EU context;

- dummies to detect regional heterogeneity. Similarly, these are meaningless for EU countries.

As a result, it is possible to summarize the model used in this study as

$$
\text { GROW }=f(G D P, E D U C, L E ; F R, G O V, I N F),
$$

with $f($.$) a function of, GROW growth, EDUC the secondary education level, L E$ life expectancy at birth, $F R$ fertility rate, $G O V$ the government consumption ratio and INF the inflation rate. All these conditions, our source data and transformations are explained below. Original data were retrieved for all 28 countries from Eurostat. The conditions used are as follows:

\section{Growth (GROW)}

To measure this condition, we used the real GDP index provided by Eurostat. We calculated the annual average growth rate for each country's GDP between 2000 and 2013. Using the data provided by Eurostat for the EU28, we calculated the overall EU growth rate. Each country is considered to be converging if its growth is greater than EU growth.

\section{$G D P$}

According to Barro (1996), GDP could be a determinant of convergence, because countries with lower GDP levels are expected to have quicker growth. For this condition, we considered the initial per capita GDP level (in purchasing power parity).

Secondary education level (EDUC)

This study considers the percentage of the population aged between 15 and 64, with at least secondary education. As data for this condition is only available from 2004 onwards, this is the only condition which is not calculated from 2000. The condition was calculated by averaging values from 2004 to 2013. 


\section{Life expectancy at birth (LE)}

This is measured as average life expectancy at birth for the time span in our analysis. Croatia has no data available for 2000 and the EU28 and Latvia have no data for 2000 and 2001.

\section{Fertility rate (FR)}

This condition considers average fertility rates for all countries during the time span we analyze. There is no data available for France in 2013 or for the EU28 and Croatia in 2000 .

\section{Government consumption ratio (GOV)}

This condition considers the final general government consumption expenditure between 2000 and 2013, measured as an average percentage of GDP. Lithuania only has data available for this from 2004 onwards.

\section{Inflation rate (INF)}

The average inflation rate was calculated for each country and for the EU28. This was calculated based on the HICP index.

csQCA is a comparative technique which considers only binary conditions, which implies transforming the outcome and the conditions. For both the outcome and conditions, each country wascompared with EU28. The cut-off point was the median for the EU28, which means that if a country's original variable was equal to or greater than the EU28 median, that outcome/condition took the value 1 . On the other hand, if a country's original variable was below the EU28 median, the outcome/condition took the value 0 . As we have a relatively small sample, it is preferable to use the median as a benchmark rather than the mean, because the median is less sensitive to outliers. Table 1 summarizes the information and data included in the current version of the fs/QCA software package (2.5) to obtain our estimations.

After analysing the necessary and sufficient conditions for growth rates, and considering just the countries which, at the beginning of the analysis, have a GDP lower than the EU28 level (i.e. for which GDP=0), we are able to establish the conditions for convergence. For these countries, if GROW $=1$, than they grow more than the EU28, which means that they converge. This is true for Bulgaria, the Czech Republic, Estonia, Croatia, Latvia, Lithuania, Malta, Poland, Romania, Slovenia and Slovakia. On the other hand, if GROW =0, the countries diverge from the EU28 (Greece, Hungary and Portugal).

Because these countries all have GDP $=0$, the model is resumed to:

$$
G R O W=f(E D U C, L E ; F R, G O V, I N F),
$$

As mentioned in the introduction, the use of csQCA in studies about economic growth and convergence is rare. Only the studies by Haynes $(2014,2015)$ work directly with this method, although they also use cluster analysis. 
Table 1. Values for the outcome and conditions, forcsQCA analysis of growth rates.

\begin{tabular}{|c|c|c|c|c|c|c|c|}
\hline Country & GROW & GDP & EDUC & LE & $\mathrm{FR}$ & GOV & INF \\
\hline Belgium & 0 & 1 & 0 & 1 & 1 & 1 & 0 \\
\hline Bulgaria & 1 & 0 & 1 & 0 & 0 & 0 & 1 \\
\hline Czech & 1 & 0 & 1 & 0 & 0 & 1 & 0 \\
\hline Denmark & 0 & 1 & 0 & 0 & 1 & 1 & 0 \\
\hline Germany & 0 & 1 & 1 & 1 & 0 & 0 & 0 \\
\hline Estonia & 1 & 0 & 1 & 0 & 1 & 0 & 1 \\
\hline Ireland & 1 & 1 & 0 & 0 & 1 & 0 & 0 \\
\hline Greece & 0 & 0 & 0 & 1 & 0 & 1 & 1 \\
\hline Spain & 0 & 1 & 0 & 1 & 0 & 0 & 1 \\
\hline France & 0 & 1 & 0 & 1 & 1 & 1 & 0 \\
\hline Croatia & 1 & 0 & 1 & 0 & 1 & 1 & 1 \\
\hline Italy & 0 & 1 & 0 & 1 & 0 & 1 & 0 \\
\hline Cyprus & 0 & 1 & 0 & 1 & 1 & 0 & 0 \\
\hline Latvia & 1 & 0 & 1 & 0 & 0 & 0 & 1 \\
\hline Lithuania & 1 & 0 & 1 & 0 & 0 & 0 & 1 \\
\hline Luxembourg & 1 & 1 & 0 & 1 & 1 & 0 & 1 \\
\hline Hungary & 0 & 0 & 1 & 0 & 0 & 1 & 1 \\
\hline Malta & 1 & 0 & 0 & 1 & 1 & 0 & 0 \\
\hline Netherlands & 0 & 1 & 0 & 1 & 1 & 1 & 0 \\
\hline Austria & 0 & 1 & 1 & 1 & 0 & 1 & 0 \\
\hline Poland & 1 & 0 & 1 & 0 & 0 & 0 & 1 \\
\hline Portugal & 0 & 0 & 0 & 0 & 0 & 1 & 1 \\
\hline Romania & 1 & 0 & 1 & 0 & 1 & 0 & 1 \\
\hline Slovenia & 1 & 0 & 1 & 0 & 0 & 0 & 1 \\
\hline Slovakia & 1 & 0 & 1 & 0 & 0 & 0 & 1 \\
\hline Finland & 0 & 1 & 0 & 1 & 1 & 1 & 0 \\
\hline Sweden & 1 & 1 & 1 & 1 & 1 & 1 & 0 \\
\hline UK & 0 & 1 & 0 & 1 & 1 & 1 & 0 \\
\hline
\end{tabular}

Source: author's calculations 
Haynes (2014) studies how the euro crisis starting in 2010 can be understood as evidence of the failure of macroeconomic policy to result in convergence, resulting instead in national macroeconomic trends and outcomes diverging. Combining csQCA with cluster analysis, that study concludes that for the period analyzed, the EU demonstrates divergence. Haynes (2015) also combines the same two methodologies to examine whether there is evidence that the Eurozone countries have experienced economic convergence. Once again, the study finds little evidence of convergence. The objective of our study, however, is not to study the possibility of convergence but to establish what conditions may promote that convergence.

\section{Results}

Firstly, we applied csQCA to all the EU countries. Table 2 shows the results of the necessary conditions for each country to grow more than the EU28, on the left (first two numeric columns) for those that have grown. The results for countries that have not grown are shown on the right. A note on the two measures that are used: consistency and coverage. Consistency captures the degree to which a relation of necessity (or sufficiency) between one or more conditions and a given outcome is met, according to the dataset (Ragin, 2006). In other words, and in the specific case of necessary conditions, it is a measure of the quality of that condition. In csQCA, it measures the proportion of cases in which the given condition is in the outcome set. As for coverage, it is a measure of the empirical relevance of the result and is calculated as the proportion of cases of the outcome that are represented by the given condition (Ragin, 2008).

Table 2. Necessary conditions for growth and for the negation of growth

\begin{tabular}{lcccc}
\hline \multicolumn{2}{c}{ Outcome: GROW } & \multicolumn{2}{c}{ Outcome: $\sim$ GROW } \\
\hline \multicolumn{1}{c}{ Condition } & Consistency & Coverage & Consistency & Coverage \\
\hline GDP & 0.2143 & 0.2143 & 0.7857 & 0.7857 \\
\hline$\sim$ GDP & 0.7857 & 0.7857 & 0.2143 & 0.2143 \\
\hline EDUC & 0.7857 & 0.7857 & 0.2143 & 0.2143 \\
\hline$\sim$ EDUC & 0.2143 & 0.2143 & 0.7857 & 0.7857 \\
\hline LE & 0.2143 & 0.2143 & 0.7857 & 0.7857 \\
\hline$\sim$ LE & 0.7857 & 0.7857 & 0.2143 & 0.2143 \\
\hline FR & 0.5000 & 0.5000 & 0.5000 & 0.5000 \\
\hline$\sim$ FR & 0.5000 & 0.5000 & 0.5000 & 0.5000 \\
\hline GOV & 0.2143 & 0.2143 & 0.7857 & 0.7857 \\
\hline$\sim$ GOV & 0.7857 & 0.7857 & 0.2143 & 0.2143 \\
\hline INF & 0.7143 & 0.7143 & 0.2857 & 0.2857 \\
\hline$\sim$ INF & 0.2857 & 0.2857 & 0.7143 & 0.7143 \\
\hline SOurce: & & &
\end{tabular}

Source: author's calculations 
From Table 2 it is possible to conclude that none of the conditions exceed the threshold of 0.80 , independently of the outcome. However, when we regard convergence as the outcome, the negations of GDP, life expectancy and government consumption have a consistency near to $0.8(0.7857)$, as does the consistency of the level of education. Although smaller than the minimal value considered by Fiss (2001), which is 0.8, these are also coherent with other theoretical approaches, such as Ragin (2006, 2008). When we look at non-convergence, the results are exactly the opposite. Note that, according to the definitions, the sum of consistency of a condition and its negation, for a given outcome, is necessarily equal to 1 (for example, the sum of consistence of GDP with GDP), while the sum of the coverage of a given condition, considering an outcome and a its negation is also equal to 1 (in this case, for example, the sum of coverage of GROW and $\sim$ GROW). However, the consistency of an outcome and its respective negation are not necessarily the opposite as in this case.

Qualitative comparative analysis also enables researchers to establish what the sufficient conditions for an outcome are, with three different solutions: parsimonious, intermediate and complex solutions. The difference between these solutions lies in how they treat logical remainders: rules that appear in the truth table - the framework to build sufficient conditions - but not in the dataset (for a more complete review on this topic see, for example, Ragin (2008). This study presents both parsimonious and intermediate solutions ${ }^{5}$. When explaining the sufficient conditions, two new concepts will be used: raw coverage and unique coverage. Raw coverage is the extent to which a condition (or combination of conditions) can explain the outcome, while unique coverage is the proportion that are explained exclusively by that condition or combination of conditions (see Ragin, 2006).

Table 3. Sufficient conditions for growth (parsimonious solution)

\begin{tabular}{lccc}
\hline Parsimonious solution & Raw coverage & Unique coverage & Consistency \\
\hline$\sim \mathrm{GOV}^{*} \sim \mathrm{LE}$ & 0.6429 & 0.5000 & 1.0000 \\
\hline$\sim \mathrm{GDP}^{*} \sim \mathrm{NNF}$ & 0.1429 & 0.1429 & 1.0000 \\
\hline INF*R & 0.2857 & 0.0714 & 1.0000 \\
\hline EDUC*FR & 0.2857 & 0.0714 & 1.0000 \\
\hline solution coverage: 1.0000 & & & \\
\hline solution consistency: 1.0000 & & & \\
\hline Source: author's calculations & & &
\end{tabular}

Source: author's calculations

\footnotetext{
${ }^{5}$ QCA approaches produce three different solutions: complex, intermediate and parsimonious. The complex solution does not use any simplifying assumptions in the model, which normally makes it hard to interpret (and so it is not used in this paper). The parsimonious solution on the contrary reduces the causal conditions to the smallest possible number. The intermediate solution includes selected assumptions by the researcher (see Ragin, 2006). In this paper we used the expected sign of the impact of the conditions in the outcome, according to Barro (1996).
} 
The parsimonious solution is presented in Table 3. The results do not present isolated conditions but combinations of conditions. The most important result is that lower government consumption and lower life expectancy are, jointly, the most important conditions for growth, and are together responsible for explaining 50\% of convergence (the value of unique coverage), with a raw convergence of about $64 \%$. The second combination joins the negations of GDP and inflation rate, according to Barro (1966). We then notice two different combinations of conditions, both including fertility rate: firstly with inflation and then with education. However, these conditions are less important than the first two pairs of conditions.

Table 4 shows the results for the intermediate solution. This set of results is not conclusive, because all conditions are included and in several kinds of combinations. However, the first combination is the most significant, with a unique coverage of around $43 \%$; this includes secondary education with a positive impact on convergence and life expectancy, government consumption ratio and GDP with a negative impact. Except for life expectancy, the other three conditions have the expected influence. The remaining combinations of conditions have lower values of unique coverage, which mean that in isolation they are less important.

Table 4. Sufficient conditions for growth (intermediate solution)

\begin{tabular}{|c|c|c|c|}
\hline Intermediate solution & Raw coverage & Unique coverage & Consistency \\
\hline$\sim \mathrm{LE}^{\star} \mathrm{EDUC}^{*} \sim \mathrm{GOV}^{*} \sim \mathrm{GDP}$ & 0.5714 & 0.4286 & 1.0000 \\
\hline $\mathrm{FR}^{\star} \mathrm{EDUC}^{*} \sim \mathrm{GDP}$ & 0.2143 & 0.0714 & 1.0000 \\
\hline$\sim \mathrm{GOV}^{*} \sim \mathrm{INF}^{*} \sim \mathrm{GDP}$ & 0.0714 & 0.0714 & 1.0000 \\
\hline$\sim \mathrm{EMV}^{*} \sim \mathrm{GOV}^{*} \sim 1 \mathrm{NF}$ & 0.0714 & 0.0714 & 1.0000 \\
\hline$E D U C^{*} \sim I N F \sim{ }^{*} G D P$ & 0.0714 & 0.0714 & 1.0000 \\
\hline $\mathrm{FR}^{*} \mathrm{LE}^{\star} \mathrm{EDUC} \mathrm{C}^{*} \sim \mathrm{INF}$ & 0.0714 & 0.0714 & 1.0000 \\
\hline $\mathrm{FR}^{*} \mathrm{LE}^{*} \sim \mathrm{GOV}^{*} \mathrm{INF}$ & 0.0714 & 0.0714 & 1.0000 \\
\hline \multicolumn{4}{|l|}{ solution coverage: 1.0000} \\
\hline solution consistency: 1.0000 & & & \\
\hline
\end{tabular}

Source: author's calculations

Despite the multiplicity of these results, we believe two important features stand out:

i) Firstly, growth seems to be most influenced by lower levels of government consumption, higher levels of education, lower GDP and lower life expectancy. This last condition contradicts the expectations of Barro (1996). However, a similar result is reported in Azomahou et al. (2009), because this condition can display endogenous behaviour. The results for government consumption and education are as expected and in line with EU objectives: budget control and efforts to make Europe the most competitive and dynamic knowledge-based economy in the world. The other condition with a positive 
influence on growth is GDP, with the expected influence (growth is easier for countries with lower GDP).

ii) Secondly, the coverage and consistency of the solution as a whole is of interest. In fact, the results for these indicators are equal to 1 in both types of solution, meaning that all our results are coherent with all the possible solutions, with no contradictions. The results are presented in Table 5 and can be read as follows: there is one country with $\mathrm{GDP}=1, \mathrm{INF}=0, \mathrm{GOV}=1, \mathrm{EDUC}=0, \mathrm{LE}=0$ and $\mathrm{FR}=1$; this country (Belgium) does not grow more than the EU. The results would show some contradiction if any other country had the same six conditions but demonstrated growth greater than the EU average. Although we have 18 possible results, as shown in Table 5, no contradiction is detected. This is a very important feature of a good csQCA result, as referred to by Rihoux and De Meur (2008) among others.

Table 5. Solution map for growth

\begin{tabular}{lccccccc}
\hline Countries & GROW & GDP & INF & GOV & EDUC & LE & FR \\
\hline Belgium, France, Finland, Netherlands, UK & 0 & 1 & 0 & 1 & 0 & 1 & 1 \\
\hline Bulgaria, Latvia, Lithuania, Poland, Slovenia, Slovakia & 1 & 0 & 1 & 0 & 1 & 0 & 0 \\
\hline Czech Republic & 1 & 0 & 0 & 1 & 1 & 0 & 0 \\
\hline Denmark & 0 & 1 & 0 & 1 & 0 & 0 & 1 \\
\hline Germany & 0 & 1 & 0 & 0 & 1 & 1 & 0 \\
\hline Estonia, Romania & 1 & 0 & 1 & 0 & 1 & 0 & 1 \\
\hline Ireland & 1 & 1 & 0 & 0 & 0 & 0 & 1 \\
\hline Greece & 0 & 0 & 1 & 1 & 0 & 1 & 0 \\
\hline Spain & 0 & 1 & 1 & 0 & 0 & 1 & 0 \\
\hline Croatia & 1 & 0 & 1 & 1 & 1 & 0 & 1 \\
\hline Italy & 0 & 1 & 0 & 1 & 0 & 1 & 0 \\
\hline Cyprus & 0 & 1 & 0 & 0 & 0 & 1 & 1 \\
\hline Luxembourg & 1 & 1 & 1 & 0 & 0 & 1 & 1 \\
\hline Hungary & 0 & 0 & 1 & 1 & 1 & 0 & 0 \\
\hline Malta & 1 & 0 & 0 & 0 & 0 & 1 & 1 \\
\hline Austria & 0 & 1 & 0 & 1 & 1 & 1 & 0 \\
\hline Portugal & 0 & 0 & 1 & 1 & 0 & 0 & 0 \\
\hline Sweden & 1 & 1 & 0 & 1 & 1 & 1 & 1 \\
\hline
\end{tabular}

Source: author's calculations

After analysing the conditions for growth, we are able to analyse the conditions for convergence. Recovering information only for those countries which had GDP $=0$, i.e., those which, at the beginning of the period under analysis, had GDP levels lower than the EU average, we apply the function given in Equation 2, and the same methods. Note 
that we can now assume that the outcomes are convergence and non-convergence because they are, the joint hypothesis and GDP $=0$ and GROW=1 (convergence) and $\mathrm{GDP}=0$ and GROW=0 (non-convergence). In Table 6 we report the necessary conditions for convergence and non-convergence; Tables 7 and 8 show the sufficient conditions for convergence (according to the parsimonious and intermediate solutions); finally, Table 9 shows the solution map for convergence.

Table 6. Necessary conditions for convergence and for non- convergence

\begin{tabular}{lcccc}
\hline & \multicolumn{2}{c}{ Outcome: Convergence } & \multicolumn{2}{c}{ Outcome: Non-convergence } \\
\hline \multicolumn{1}{c}{ Condition } & Consistency & Coverage & Consistency & Coverage \\
\hline EDUC & 0.9091 & 0.9091 & 0.3333 & 0.0909 \\
\hline$\sim$ EDUC & 0.0909 & 0.3333 & 0.6667 & 0.6667 \\
\hline LE & 0.0909 & 0.5000 & 0.3333 & 0.5000 \\
\hline$\sim$ LE & 0.9091 & 0.8333 & 0.6667 & 0.1667 \\
\hline FR & 0.3636 & 1.0000 & 0.0000 & 0.0000 \\
\hline$\sim$ FR & 0.6363 & 0.7000 & 1.0000 & 0.3000 \\
\hline GOV & 0.1818 & 0.4000 & 1.0000 & 0.6000 \\
\hline$\sim$ GOV & 0.8182 & 1.0000 & 0.0000 & 0.0000 \\
\hline INF & 0.8182 & 0.7500 & 1.0000 & 0.2500 \\
\hline$\sim$ INF & 0.1818 & 1.0000 & 0.0000 & 0.0000 \\
\hline SOurce: & & &
\end{tabular}

Source: author's calculations

Table 7. Sufficient conditions for convergence (parsimonious solution)

\begin{tabular}{lccc}
\hline Parsimonious solution & Raw coverage & Unique coverage & Consistency \\
\hline$\sim$ GOV & 0.8182 & 0.5455 & 1.0000 \\
\hline FR & 0.3636 & 0.0909 & 1.0000 \\
\hline$\sim$ INF & 0.1818 & 0.0909 & 1.0000 \\
\hline solution coverage: 1.0000 & & & \\
\hline solution consistency: 1.0000 & & & \\
\hline
\end{tabular}

Source: author's calculations

The results for the necessary conditions show that higher education levels and lower life expectancy have a consistency level greater than 0.9 , which means that they are very important conditions for convergence. Lower levels of government expenditures have a consistency above 0.8 , which means that this is also a very important condition. These results were the same as in the growth analysis, but with reinforced consistency. As for non-convergence, we find three necessary conditions for that outcome: low fertility rates, higher government expenditures and higher inflation. The results of government expenditures and inflation are in line with Barro's evidence and also with the EU government body's expectations. The result for fertility rate is contrary to what Barro argues, 
but could be interpreted as a necessity for countries that do not converge, to promote renewal of generations.

Table 8. Sufficient conditions for convergence (intermediate solution)

\begin{tabular}{lccc}
\hline Intermediate solution & Raw coverage & Unique coverage & Consistency \\
\hline EDUC* $\sim$ GOV & 0.7273 & 0.5455 & 1.0000 \\
\hline FR*EDUC & 0.2727 & 0.0909 & 1.0000 \\
\hline EDUC* $\sim$ INF & 0.0909 & 0.0909 & 1.0000 \\
\hline LE* $^{*} \mathrm{GOV}^{*} \sim$ INF & 0.0909 & 0.0909 & 1.0000 \\
\hline solution coverage: 1.0000 & & & \\
\hline solution consistency: 1.0000 & & & \\
\hline Source: author's calculations & & &
\end{tabular}

If we turn to the results for the sufficient conditions, with the parsimonious solution we can conclude that the most important condition is the absence of government expenditures (with a raw coverage of 0.8182 and a unique coverage of 0.5455 ). Higher fertility rates and lower inflation are also sufficient conditions, but with less importance. These results are coherent with previous findings. As for the intermediate solution, then the most important sufficient conditions are the combination of education with low government expenditures and another combination of education, and fertility rate. Once again, these results are coincident with previous analysis.

Table 9. Solution map for convergence

\begin{tabular}{lcccccc}
\hline Countries & GROW & INF & GOV & EDUC & LE & FR \\
\hline Bulgaria, Latvia, Lithuania, Poland, Slovenia, Slovakia & 1 & 1 & 0 & 1 & 0 & 0 \\
\hline Czech Republic & 1 & 0 & 1 & 1 & 0 & 0 \\
\hline Estonia, Romania & 1 & 1 & 0 & 1 & 0 & 1 \\
\hline Greece & 0 & 1 & 1 & 0 & 1 & 0 \\
\hline Croatia & 1 & 1 & 1 & 1 & 0 & 1 \\
\hline Hungary & 0 & 1 & 1 & 1 & 0 & 0 \\
\hline Malta & 1 & 0 & 0 & 0 & 1 & 1 \\
\hline Portugal & 0 & 1 & 1 & 0 & 0 & 0 \\
\hline
\end{tabular}

Source: author's calculations

In both solutions, coverage and consistency are again equal to 1 , which means that we have no contradictions in our results, as can be seen in Table 9. 


\section{Conclusions}

This study has analysed economic growth and convergence in the European Union countries using a crisp-set qualitative comparative analysis, and has identified what conditions can be considered necessary and sufficient to make a country's growth greater than that of the EU as a whole, and convergent. This is the first paper to use this methodology to study this particular issue.

To achieve our results we used six conditions: the initial level of GDP, the level of secondary education, the life expectancy, fertility rate, level of government consumption and inflation rate. Firstly, we use the outcome variable "growth", which is verified if each country is growing faster than the median growth rate across the EU.

For the "growth" outcome, lower government consumption, higher levels of education and lower levels of life expectancy are the necessary conditions, with higher consistency values. On the other hand, to achieve the opposite outcome (lack of growth), low levels of education and higher levels of government consumption have higher consistency values as necessary conditions. While the conditions related to education and government consumption are easily understood, the necessary condition of life expectancy seems somewhat contradictory. Nevertheless, it is important to note that life expectancy is commonly used to distinguish between developed and developing countries. As we are analysing the EU, which is composed of developed countries alone, this condition may not be so relevant. Furthermore, many of the countries with lower life expectancies are also those which have lower base GDP values, which may explain this contradictory result.

In terms of sufficient conditions, the results do not present isolated conditions but combinations of conditions. The main combined conditions for growth are lower levels of government consumption, life expectancy and GDP, combined with high levels of education. Except for life expectancy, as explained above, these conditions have the influence on growth we had expected.

After analyzing the growth patterns, we proceeded evaluate the convergence level. In this case, we only examined those countries which, at the beginning of the analysis, had a GDP lower than the average across the EU. Hence, if one of these countries was to grow at more than the EU average, it would be converging, while it would be diverging if the opposite was happening. We found that the most relevant necessary conditions for convergence are higher education levels, lower levels of life expectancy and low government expenditures. Alone or combined with education, according to the type of solution, low government expenditure is the most important sufficient condition for convergence. Lower fertility rates, higher government expenditures and higher inflation are necessary conditions for non-convergence.

Our results are innovative because, despite being in accordance with EU expectations (to promote economic growth by raising levels of education and keeping a disciplined government budget), they help us to understand the type of policies that countries should pursue in order to attain better growth rates and economic convergence. Obviously it is not realistic to encourage political decision-makers to lower the GDP and life expectancy in their countries: rather, our results reveal that it is easier for countries with lower levels of GDP to grow, while life expectancy is related to GDP. However what is 
clear is that investment in education is essential if growth is to be increased. Our results also support the idea that countries should be more conservative in their public accounts, in order to achieve economic growth and convergence.

Acknowledgements: The authors are pleased to acknowledge financial support from Fundação para a Ciência e a Tecnologia (grant UID/ECO/04007/2013) and FEDER/COMPETE (POCI-01-0145-FEDER-007659)

Disclosure statement: No potential conflict of interest was reported by the authors.

\section{References}

AGHION, P., HOWITT, P., MAYER-FOULKES, D. (2005). The effect of financial development on convergence: Theory and evidence. Quarterly Journal of Economics, 120(1), 173-222.

AZOMAHOU, T., BOUCEKKINE, R., DIENE, B. (2009). A closer look at the relationship between life expectancy and economic growth. International Journal of Economic Theory, 5(2), 201-244.

BADUNENKO, O., HENDERSON, D., RUSSELL, R. (2013). Polarization of the worldwide distribution of productivity. Journal of Productivity Analysis, 40, 153-171

BARRO, R. (1991). Economic growth in a cross section of countries. Quarterly Journal of Economics, 106, 407-443.

BARRO, R. (1996). Determinants of economic growth: a cross-country empirical study. NBER Working Paper 5698.

BARRO, R. (2016). Economic growth and convergence, applied especially to China. NBER working paper 21872.

BARRO, R., SALA-I.MARTIN, X. (1992). Convergence. Journal of Political Economy. 100, 223-51. DOI: $10.1086 / 261816$

BARRO, R., SALA-I.MARTIN, X., BLANCHARD, O., HALL, R. (1991). Convergence across states and regions, Brookings Papers on Economic Activity, 1, 107-58. DOI: $10.2307 / 2534639$

BARTKOWSKA, M., RIEDL, A. (2012). Regional convergence clubs in Europe: Identification and conditioning factors. Economic Modelling. 29, 22-31. DOI: $\underline{10.1016 / \text { j.econmod.2011.01.013 }}$

BATTISTI, M., DE VAIO, G. (2008). A spatially filtered mixture of $\beta$-convergence regressions for EU regions, 1980-2002. Empirical Economics, 34(1), 105-121 DOI: $\underline{10.1007 / \mathrm{s} 00181-007-0168-8}$

BAUMOL, W. (1986). Productivity growth, convergence, and welfare: what the longrun data show. American Economic Review, 76 (5), 1072-1085.

BERNARD, A., DURLAUF, S. (1995). Convergence in International Output. Journal of Applied Econometrics. 10(2), 97-108. DOI: 10.1002/jae.3950100202 
BRADA, J., KUTAN, A., ZHOU, S. (2005). Real and monetary convergence between the European Union's core and recent member countries: A rolling cointegration approach. Journal of Banking \& Finance. 29, 249-270. DOI: 10.1016/j.jbankfin.2004.06.024

CARLINO, G., MILLS, L. (1993). Are U.S. regional incomes converging? A time series analysis. Journal of Monetary Economics. 32, 335-346. DOI: 10.1016/03043932(93)90009-5

CARLINO, G., MILLS, L. (1996). Convergence and the U.S. States: a time-series analysis. Journal of Regional Science. 36, 597-616. DOI: 10.1111/j.14679787.1996.tb01120.x

CARRION-I-SILVESTRE, J., GERMAN-SOTO, V. (2007). Stochastic convergence amongst Mexican states. Regional Studies. 41, 531-541. DOI: 10.1080/00343400601120221

CUARESMA, J., DOPPELHOFER, G., FELDKIRCHER, M. (2014). The Determinants of Economic Growth in European Regions. Regional Studies, 48(1), 44-67. DOI: $\underline{10.1080 / 00343404.2012 .678824}$

DURLAUF, S., JOHNSON, P., TEMPLE, J. (2005). Growth econometrics, in (P. Aghion and S.N. Durlauf, eds.), Handbook of Economic Growth, Amsterdam: North Holland.

DURLAUF, S., KOURTELLOS, A., TAN, C. (2008). Are any growth theories robust? The Economic Journal, 118, 329-346. DOI: 10.1111/j.1468-0297.2007.02123.x

EVANS, P., KARRAS, G. (1996). Convergence revisited, Journal of Monetary Economics. 37, 249-65. DOI: 10.1016/S0304-3932(96)90036-7

FISS, P. (2007). A set-theoretic approach to organizational configurations. Academy of Management Review, 32(4), 1180-1198. DOI: 10.5465/AMR.2007.26586092

FISS, P. (2011). Building better causal theories: a fuzzy set approach to typologies in organization research. Academy of Management Journal, 54 (2), 393-420. DOI: 10.5465/AMJ.2011.60263120

HAYNES, P. (2014). Combining the Strengths of Qualitative Comparative Analysis with Cluster Analysis for Comparative Public Policy Research: With Reference to the Policy of Economic Convergence in the Euro Currency. Area International Journal of Public Administration, 37(9), 581-590, DOI: 10.1080/01900692.2014.880849

HAYNES, P. (2015). The European Single Currency Project and the Concept of Convergence for European Welfare States - The Ideal and the Reality. Social Policy \& Administration, 49(4), 466-489 .

HENDERSON, D., RUSSELL, R. (2005). Human capital and convergence: a production-frontier approach. International Economic Review, 46 (4), 1167-1205

JOHNSON, P. (2005). A continuous state space approach to convergence by parts. Economics Letters, 86, 317-321. 
KUMAR, S., RUSSELL, R. (2002). Technological change, technological catch-up, and capital deepening: relative contributions to growth and convergence. American Economic Review, 92(3), 527-548.

LOEWY, M., PAPELL, D. (1996). Are US regional incomes converging? Some further evidence. Journal of Monetary Economics. 38, 587-598.

LUCAS, R. (1988). On the mechanics of economic development. Journal of Monetary Economics, 22, 3-42.

MONTAÑÉS, A., OLMOS, L. (2014). Do the Spanish regions converge? A unit root analysis for the HDI of the Spanish regions. Applied Economics. 46, 4218-4230.

NAHAR, S., INDER, B. (2002). Testing convergence in economic growth for OECD countries. Applied Economics. 34, 2011-2022. DOI: 10.1080/00036840110117837

OWEN, A., VIDERAS, J., DAVIS, L. (2009). Do all countries follow the same growth process? Journal of Economic Growth, 14(4), 265-286.

PAAP, R., FRANSES, P., VAN DJIK, D. (2005). Does Africa grow slower than Asia, Latin America and the Middle East? Evidence from a new data-based classification method. Journal of Development Economics, 77 (2), 553-570.

QUAH, D. (1993). Galtons fallacy and tests of the convergence hypothesis. Scandinavian Journal of Economics, 95 (4), 427-443.

QUAH, D. (1996). Twin peaks: growth and convergence in models of distribution dynamics. Economic Journal, 106 (437), 1045-1055.

QUAH, D. (1997). Empirics for growth and distribution: stratification, polarization, and convergence clubs. Journal of Economic Growth, 2(1), 27-59.

RAGIN, C. (1987). The Comparative Method: Moving beyond Qualitative and Quantitative Strategies. Berkeley: University of California Press.

RAGIN, C. (2006). Set relations in social research: Evaluating their consistency and courage. Political Analysis, 14, 291-310. DOI: 10.1093/pan/mpj019

RAGIN, C. (2008). Redesigning Social Inquiry: Fuzzy Sets and Beyond. Chicago: The University of Chicago Press.

RIHOUX, B., DE MEUR, G. (2008). Cirsp-set qualitative comparative analysis (csQCA), in Rihoux, B. and Ragin, C. (Eds) Configurational Comparative Methods Qualitative Comparative Analysis (QCA) and related techniques. Thousand Oaks, CA: Sage.

ROMER, P. (1990). Human Capital and Growth: Theory and Evidence. CarnegieRochester Conference Series on Public Policy, 32, 251-286. DOI: 10.1016/01672231(90)90028-J

SALA-I-MARTIN, X., DOPPELHOFER, G., MILLER, R. (2004). Determinants of long-term growth: a Bayesian averaging of classical estimates (BACE) approach. American Economic Review, 94(4), 813-35. 
SOLOW, R. (1956). A contribution to the theory of economic growth. Quarterly Journal of Economics, 70 (1), 65-94.

STRAZICHICH, M., LEE, J., DAY, E. (2004). Are incomes converging among OECD countries? Time series evidence with two structural breaks. Journal of Macroeconomics. 26, 131-145.

VIS, B. (2012). The Comparative Advantages of fsQCA and Regression Analysis for Moderately Large-N Analyses. Sociological Methods \& Research, 41(1), 168-98.

VIS, B., WOLDENDORP, J., KEMAN, H. (2007). Do miracles exist? Analyzing economic performance comparatively. Journal of Business Research. 60, 531-538.

WALHEER, B. (2016). Growth and convergence of the OECD countries: A multisector production-frontier approach. European Journal of Operational Research (forthcoming) DOI: 10.1016/j.ejor.2016.01.030 